\title{
Masticatory Function and Post-Pleistocene Evolution in Nubia 1
}

\author{
DAVID S. CARLSON AND DENNIS P. VAN GERVEN \\ Center for Human Growth and Development, The University of Michigan, Ann \\ Arbor, Michigan 48109 and Department of Anthropology, University of \\ Colorado, Boulder, Colorado 80302
}

\section{KEY WORDS Mastication · Craniofacial evolution · Nubia}

\begin{abstract}
The present research focuses on craniofacial variation in Nubia over approximately 10,000 years. Samples were grouped according to their temporal location and subsistence pattern, and represent a transition from a huntinggathering adaptation (Mesolithic) to a transitional hunting-gathering-agricultural adaptation (A-C Group) and finally to a fully agricultural adaptation (Meroitic/XGroup/Christian). The purposes were: (1) to compare the Mesolithic sample with the later Nubian populations; and (2) to evaluate further the hypothesis that change in Nubian craniofacial morphology was due to changing functional demands associated with the progressive change in subsistence adaptation and associated behavior.

The results tend to support recent views that the Nubian Mesolithic population is probably ancestral to later Nubian groups, and that the masticatory-functional hypothesis can best account for craniofacial change among the Nubians since 12,000 B.P. According to this hypothesis systematic reduction in functional demand placed on the masticatory complex from the Mesolithic led, secondarily, to an alteration of the growth of the maxillomandibular complex such that the face became progressively less robust and more inferoposteriorly located relative to the cranial vault. Both the increase in the height of the vault relative to its length, producing a more "globular" appearance, and the reduction in dental size were tertiary, compensatory responses to altered facial size and position.
\end{abstract}

The prehistory of Lower Nubia has traditionally been explained in terms of invasion, racial type, and racial admixture. Cultural and biological change during the late Pleistocene transition was thought to be primarily the result of admixture between two "pure" racial types, Caucasoids to the north and Negroids to the south (Morant, '25, '35; Burnor and Harris, '68; Crichton, '66; Billy, '75). Similarly, biocultural change during the past 5,000 years was explained by the successive migration of alien peoples into Lower Nubia. These views notwithstanding, there is no substantial body of data to support either the "racial admixture hypothesis" of cultural and biological change during the late Paleolithic-Mesolithic or the "multiple-mi- gration hypothesis" of change during the past 5,000 years in Lower Nubia to the exclusion of the hypothesis that temporal change was due to in situ evolution. In fact, the bulk of the archaeological and biological evidence now supports the latter view, i.e., that those changes in cultural traditions and in morphology of the populations of Lower Nubia, at least since the Mesolithic (c. 12,000 B.P.), were due to the process of evolution rather than to admixture and/or invasion by alien peoples (Adams, '67, '70; Greene, '66, '72; Van Gerven et al., '73; Carlson, '76a).

\footnotetext{
${ }^{1}$ This research was supported in part by Grant-In-Aid 2959 from the Wenner-Gren Foundation for Anthropological Research. United States Public Health Service Grants DE03610 and DE00193, and by NIH Post-Doctoral Fellowship DE05101.
} 
Recent studies (Vagn Nielsen, '70; Carlson, '74a,b, '76a,b) emphasized the nature of craniofacial variation among indigenous Nubian populations over the past 5,000 years within an evolutionary framework. Carlson (74a,b, '76a,b) showed that change in the form of the Nubian skull during this time can be accounted for by three relatively independent patterns of morphological variation. The major pattern of change resulted in a "rotation" of the cranial vault and face about the median cranial base such that the vault became relatively shorter, higher, and more anterosuperiorly located relative to the face. The midface and lower face underwent a concomitant change in position to become more inferoposteriorly located. Finally, the size and position of the muscles of mastication, as determined by their sites of bony attachment, underwent a reduction and re-orientation from the earlier groups through the later populations, causing change in the vault-face spatial relationship. The causal interrelationships of these three patterns of craniofacial change were not discussed. However, Carlson (76a,b) hypothesized that the change in the masticatory complex was primarily due to alterations of masticatory function and related behavioral changes associated with a transition from a pre-agricultural hunting-gathering form of subsistence to a fully agricultural subsistence pattern. These working hypotheses were directed only at the potential selective factors acting on the phenotypic expression of craniofacial morphology in Nubia, and did not attempt to articulate progressive craniofacial change within a genetic model. Thus, emphasis was placed on the possible evolutionary determinants of such change. This conceptual framework permits insight into the evolutionary dynamics of biological and cultural variation within the Nubian corridor, a subject which has been unduly constrained by earlier racial interpretations.

\section{Problem}

The purpose of the present research is to extend the analysis of craniofacial variation and evolution in Lower Nubia to the $\mathrm{Nu}$ bian Mesolithic by comparing the Mesolithic population with later indigenous Nubian groups. The rationale for the research is 2-fold. (I) The relationships of the Nubian Mesolithic population to more recent Nubian groups has received only limited treatment. (2) The previously stated hypotheses relating changes in masticatory function to relatively specific variation in craniofacial architecture can be further evaluated and refined using the Mesolithic sample. The remains analyzed in this study represent a temporal sequence from a hunting-gathering adaptation to an incipient agricultural adaptation followed by a fully agricultural adaptation. Assuming the validity of the stated hypotheses, there should be two distinct results from this study: (a) an identifiable trend of craniofacial variation with the agricultural population at one extreme and the Mesolithic hunting-gathering population at the other; and (b) the morphological patterns associated with this trend should be noticeably similar to those previously suggested for the later Nubian populations (Carlson, '74a,b, '76a).

\section{MATERIALS}

Craniometric data in this study were obtained from remains of three major cultural periods during Nubian prehistory. The Mesolithic sample was excavated by the University of Colorado Nubian Expedition (1963-1964) from a single site (6-B-36) near the modern village of Wadi Halfa. Faunal analysis indicates a heavy reliance by the inhabitants on large game hunting, with some fishing and seed gathering also in evidence. Absolute dating of the Mesolithic sample was not possible due to the permineralization of the organic remains. However, lithic comparisons between the microlithic tools of the Wadi Halfa site and the Quadan industry (Wendorf et al., '65) indicate a close temporal relationship of these two industries (Greene and Armelagos, '72). $\mathrm{C}^{14}$ dates associated with the Quadan industry reported by Wendorf et al. ('65) range be- 
TABLE 1

Means and standard deviations for 16 variables describing the craniofacial morphology of three Nubian populations (in $\mathrm{cm}$ )

\begin{tabular}{|c|c|c|c|c|c|c|c|}
\hline \multirow{2}{*}{ Variable } & \multicolumn{3}{|c|}{ Mesolithic } & \multicolumn{2}{|c|}{ A.C group } & \multicolumn{2}{|c|}{ MXCh group } \\
\hline & $\bar{x}$ & S.D. & $\mathrm{N}$ & $\bar{x}$ & S.D. & $\overline{\mathrm{x}}$ & S.D. \\
\hline 1. Cranial length & 18.58 & 0.32 & 12 & 18.18 & 0.64 & 18.27 & 0.82 \\
\hline 2. Cranial height & 12.75 & 0.56 & 7 & 13.91 & 0.66 & 13.64 & 0.64 \\
\hline 3. Frontal chord & 10.57 & 0.29 & 12 & 11.70 & 0.45 & 11.47 & 0.55 \\
\hline 4. Parietal chord & 11.32 & 0.35 & 12 & 0.48 & 0.49 & 12.35 & 0.70 \\
\hline 5. Facial length & 10.36 & 0.35 & 6 & 10.00 & 0.47 & 10.28 & 0.57 \\
\hline 6. Upper face height & 6.63 & 0.33 & 7 & 6.68 & 0.40 & 6.66 & 0.43 \\
\hline 7. Cheek height & 2.57 & 0.23 & 10 & 2.42 & 0.26 & 2.37 & 0.27 \\
\hline 8. Masseter origin length & 4.31 & 0.52 & 8 & 3.38 & 0.34 & 3.18 & 0.32 \\
\hline 9. Ramus height & 4.75 & 0.62 & 10 & 4.51 & 0.42 & 4.55 & 0.45 \\
\hline 10. Corpus length & 9.25 & 0.41 & 12 & 7.37 & 0.57 & 7.20 & 0.50 \\
\hline I1. Symphysis height & 3.35 & 0.22 & 12 & 3.19 & 0.38 & 3.28 & 0.37 \\
\hline 12. Symphysis thickness & 1.69 & 0.17 & 12 & 1.48 & 0.14 & 1.44 & 0.18 \\
\hline 13. Ramal width & 4.29 & 0.37 & 12 & 3.70 & 0.38 & 3.73 & 0.30 \\
\hline 14. Sigmoid notch height & 4.67 & 0.64 & 12 & 4.40 & 0.40 & 4.28 & 0.37 \\
\hline 15. Coronoid process height & 6.14 & 0.54 & 12 & 5.98 & 0.53 & 5.95 & 0.53 \\
\hline 16. Total face height & 10.92 & 0.60 & 7 & 11.55 & 0.60 & 11.46 & 0.65 \\
\hline
\end{tabular}

The samples sizes $(\mathrm{N})$ are indicated only for the Mesolithic sample since it was not possible to obtain all measurements from each individual in this sample.

tween 11,950 and 6,400 B.C., indicating that the Wadi Halfa population is probably between 8,000 and 11,000 years old (Greene and Armelagos, '72). A total of 36 permineralized skeletons were recovered, most of them in very fragmentary condition. Of these, 12 adult crania were sufficiently complete for metric evaluation.

Skeletal remains for the latter two cultural periods were recovered by the Scandinavian Joint Expedition to Sudanese Nubia (1963-1964). The Scandinavian concession extended $60 \mathrm{~km}$ along the east bank of the Nile, beginning at the EgyptianSudanese border to the north, and included 73 distinct sites covering a time span of almost 5,000 years (c. 3,400 B.C. 1,100 A.D.). This period of Nubian culture history has been traditionally divided into five distinct cultural horizons. For our purposes, however, it was sufficient to distinguish only two evolutionary stages of cultural development. The first stage includes the $A$ Group (3,400-2,400 B.C.) and C-Group $(2,400-1,000$ B.C. $)$ horizons. The second encompasses the Meroitic (350 B.C. 350 A.D.), X-Group (350-550 A.D.) and Christian (550-1,100 A.D.) horizons. The A- through
TABLE 2

Discriminant classification matrix of the Mesolithic, A-Group/C-Group and Meroitic/ $X$-Croup/Christian samples

\begin{tabular}{|c|c|c|c|c|}
\hline \multirow{2}{*}{$\begin{array}{l}\text { Actual } \\
\text { group }\end{array}$} & \multicolumn{3}{|c|}{ Predicted group: } & \\
\hline & $\begin{array}{l}\text { Meso- } \\
\text { lithic: }\end{array}$ & $\begin{array}{c}\text { A.C } \\
\text { group }\end{array}$ & $\begin{array}{l}\text { MXCh } \\
\text { group }\end{array}$ & \\
\hline Mesolithic & $\begin{array}{c}12 \\
(100 \%)\end{array}$ & & & \\
\hline A-C group & & $\begin{array}{c}36 \\
(69 \%)\end{array}$ & $\begin{array}{c}16 \\
(31 \%)\end{array}$ & \\
\hline MXCh group & & $\begin{array}{c}51 \\
(27 \%)\end{array}$ & $\begin{array}{c}137 \\
(72 \%)\end{array}$ & \\
\hline Total & & & & $\begin{array}{c}185^{1} \\
(73.4 \%)\end{array}$ \\
\hline
\end{tabular}

The top number indicates the actual number of individuals classified into cach population. The number in parentheses indicates the percentage of each sample classified into each of the three populations. All cases had equal prior probability of belonging to each of the three samples.

Degrees of freedom $=251$.

${ }^{1}$ Chi-square $=749.04(\mathrm{P}<0.01)$

C-Group (A-C) represents, initially, a transition from a hunting-gathering subsistence to a primarily agricultural subsistence pattern and tribal organization (Adams, '70). The Meroitic-Christian (MXCh) period is characterized by a fully agricultural subsist- 


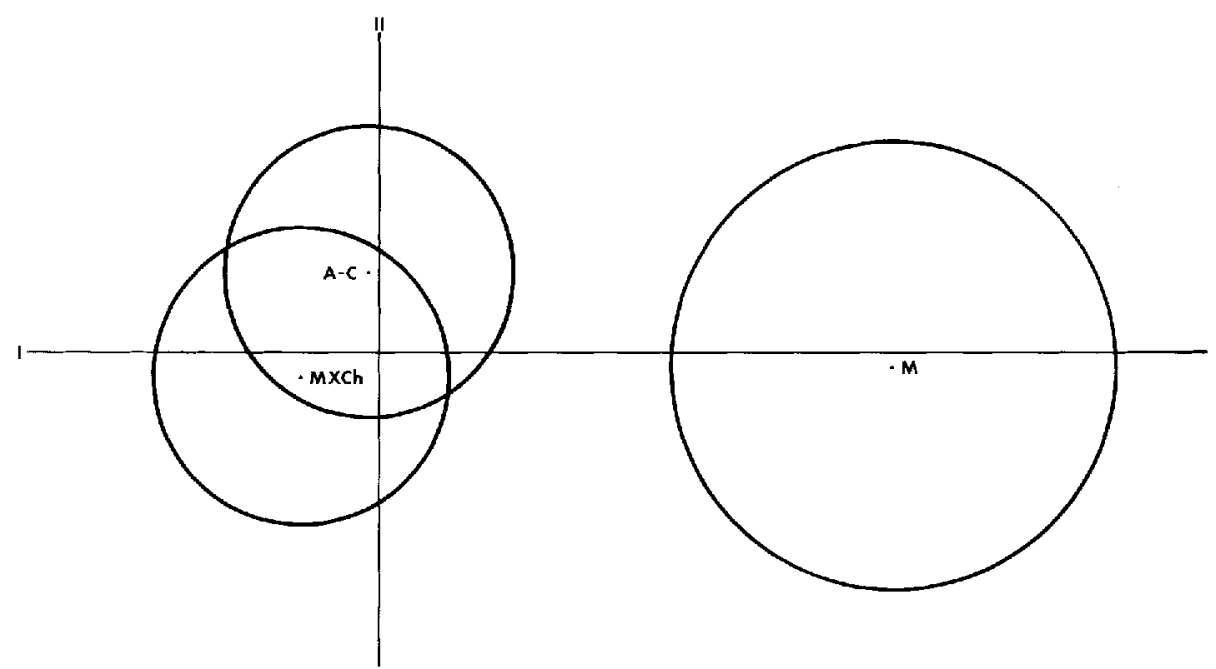

Fig. 1 Plot of the group centroids and ranges of variation for the $z$-scores of the Mesolithic, A-C and MXCh samples along the first two discriminant axes. Note that the relative position of the threc samples tends to approximate their temporal relationships.

ence and a state organization (Adams, 70 ).

Sample sizes for the A-C period and $\mathrm{MXCh}$ period are relatively large. A total of 1,500 individuals from these two stages were recovered by the Scandinavian Expedition. Of these, 52 adult male and female crania were available for analysis from the A-C period and 188 were available from the MXCh period.

\section{METHODS}

Sixteen measurements of anteroposterior craniofacial dimensions were recorded for each complete skull using standard anthropometric techniques (table 1). A-C and MXCh period crania were all complete. However the relatively poor condition of the Mesolithic sample precluded taking every measurement for each individual. The number of Mesolithic individuals for which each measurement was taken is listed in table 1.

Summary statistics were computed for each skeletal sample to demonstrate percentage change in craniofacial dimensions (table 1). All data were then subjected to a multiple discriminant analysis for further evaluation of temporal-morphological relationships. Missing values were not included in either computation.

\section{RESULTS}

\section{Population differentiation}

The effectiveness of multiple discriminant analysis in separating the three populations is summarized in the discriminant classification matrix (table 2 ). A total of 185 crania $(73.4 \%)$ were correctly assigned to their respective populations on the basis of the 16 metric variables. The Mesolithic crania were totally separated from the A-C and MXCh populations, with considerable overlap between the latter two. Such overlap was expected, however, due to the close temporal proximity of A-C and MXCh groups as compared to the Mesolithic sample. Despite this overlap, the differences among all three samples were significant at the $99 \%$ confidence level.

\section{Canonical variates}

Close inspection of the discriminant functions, or canonical variates, provided much greater insight into the nature of the relationships between the three populations. Since the maximum valid number of canonical variates is one less than the number of populations, only the first two were analyzed. Examination of the eigenvalues and Chi-square for these two functions 


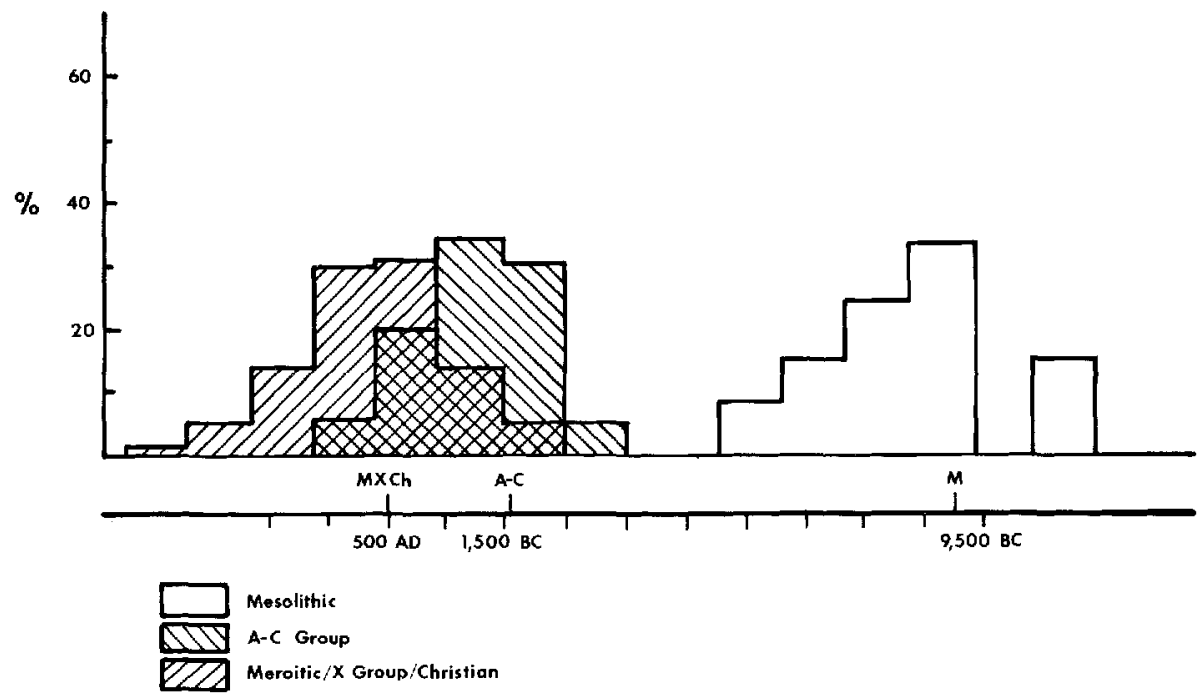

Fig. 2 Graphic representation of the distribution of individual $z$-scores (in percent) for the Mesolithic, A-C and MXCh samples along the first canonical axis. The lower line provides a time scale which was contrived to fit the observed distribution. Assuming approximately a 2,100 year separation between the MXCh and A-C Group samples, it is possible to predict the location of the Mesolithic population along this axis. It must be stressed, however, that this figure is only a heuristic device designed to emphasize the temporal nature of the first variate.

indicated that only the first function was statistically significant $(\mathrm{P}<0.01)$.

The graphic representation of the group centroids about the first two axes for the three populations indicates that the first canonical axis effectively separates the three populations (fig. 1). The first function was also most important in explaining the morphological variability between the three populations. It alone accounted for $85.3 \%$ of the variability. The amount of overlap between the two most recent populations along this axis is relatively extensive, and is consistent with the approximately $30 \%$ misclassification of individuals between these two groups.

A critically important feature of the first axis is that it orients the three populations according to their relative temporal positions. A time scale artificially imposed on the first axis demonstrates this relationship even more fully. Figure 2 provides a graphic representation of this possibility. The distribution of individual discriminant scores $\left(z^{\prime} s\right)$ for the three populations shows an extensive overlap between the $A-C$ and MXCh populations and a complete separa- tion of the Mesolithic population. The center of the distribution, which approximates the group centroid on the first discriminant axis, can be plotted for each group. Assuming an approximate mean separation of 2,100 years between the A-C and MXCh populations, and a linear relationship between change in craniofacial morphology and time, it is possible to predict the location of the Mesolithic population along this axis. According to this approach the Mesolithic population would be given a mean date of approximately 9,000 B.C. - very close to the date suggested archaeologically. It is important to emphasize that this temporal projection is not proposed as a dating technique! There is no suggestion that change in the morphology of the skull has been linear with time, and the imposition of such a scale on the first canonical axis should be perceived only as a heuristic device to emphasize the apparent diachronic nature of this function. Howver, the first axis does represent craniofacial variability as a time related phenomenon between the Mesolithic period and the MXCh period. As hypothesized, these two 
populations occupy the extremes of the first variate, with the A-C population remaining intermediate but relatively closer to the MXCh population.

\section{TABLE 3}

Summary table and standardized canonical coefficients for 16 craniofacial variables along the first discriminant axis

\begin{tabular}{lc}
\hline Eigenvalue & 1.71 \\
Canonical correlation & 0.79 \\
Percent trace & 85.30 \\
Chi-Square & 143.70 \\
Degrees of freedom & 32 \\
Significance & $\mathrm{P}<0.01$ \\
\hline 1. Cranial length & $0.40^{1}$ \\
2. Cranial height & -0.04 \\
3. Frontal chord & $-0.42^{1}$ \\
4. Parietal chord & -0.22 \\
5. Facial length & $-0.49^{1}$ \\
6. Upper facial height & $0.20^{1}$ \\
7. Cheek height & -0.24 \\
8. Masseter origin length & $0.48^{1}$ \\
9. Ramus height & -0.17 \\
10. Corpus length & $1.15^{1}$ \\
11. Symphyseal height & $0.53^{1}$ \\
12. Symphyseal thickness & 0.14 \\
13. Ramal width & 0.05 \\
14. Sigmoid notch height & $0.50^{1}$ \\
15. Coronoid process height & $-0.39^{1}$ \\
16. Total facial height & $-0.82^{1}$ \\
\hline
\end{tabular}

${ }^{i}$ Variables showing substantial weighting.

\section{Interpretation}

Standardized canonical coefficients for each variable can be taken to indicate the relative contribution of the variable to the discriminant function, thus facilitating interpretation of the biological meaning of discriminant axis. Close inspection of the weighted coefficients should reveal the morphological pattern on which the discrimination is based.

Eight variables were judged to be substantially weighted and thus primary contributors to the first discriminant axis (table 3). All regions of the craniofacial complex were represented, although the most important variables were those that defined the size and shape of the mandible relative to the height of the face and vault.

The general pattern of craniofacial variation indicated by the first function can be outlined as follows. The size of the mandibular corpus, height of the ramus, length of the cranial vault and size of the origin of the masseter muscle all covaried together and in the same direction, i.e., metric variation in each of these areas tended to be associated with directionally similar variation in all. Three other variables defining the height and length of the face and vault also covaried together, but in an inverse

TABLF 4

Change in craniofacial dimensions from the Mesolithic period through the A-Group/C-Group period and Meroitic/X-Group/Christian period (in percent)

\begin{tabular}{lcrc}
\hline \multicolumn{1}{c}{ Variable } & $\begin{array}{c}\text { Mesolithic/A-C } \\
\text { Group }\end{array}$ & $\begin{array}{c}\text { A-C Gronp/MXCh } \\
\text { Group }\end{array}$ & Total \\
\hline 1. Cranial length ${ }^{1}$ & -2.2 & 0.05 & -1.7 \\
2. Cranial height & 8.4 & -2.0 & 6.4 \\
3. Frontal chord ${ }^{1}$ & 9.7 & -2.0 & 7.9 \\
4. Parietal chord & 9.3 & -1.1 & 8.4 \\
5. Facial length ${ }^{1}$ & -3.5 & 2.8 & 0.8 \\
6. Upper face height & 0.8 & -0.3 & 0.5 \\
7. Cheek height & -5.9 & -2.1 & -7.8 \\
8. Masseter origin length ${ }^{2}$ & -21.6 & -6.0 & -26.3 \\
9. Ramus height & -3.8 & -0.5 & -4.3 \\
10. Corpus length & -20.4 & -2.4 & -22.8 \\
11. Symphysis height & -4.8 & 2.8 & -2.1 \\
12. Symphysis thickness & -12.5 & -2.8 & -15.3 \\
13. Ramal width & -13.8 & 0.9 & -13.1 \\
14. Sigmoid notch height ${ }^{1}$ & -5.8 & -2.8 & -8.4 \\
15. Coronoid process height & -2.7 & -0.6 & -3.1 \\
16. Total face height ${ }^{1}$ & 5.5 & -0.8 & 4.8 \\
\hline
\end{tabular}

${ }^{1}$ Variables judged to be substantially weighted. 


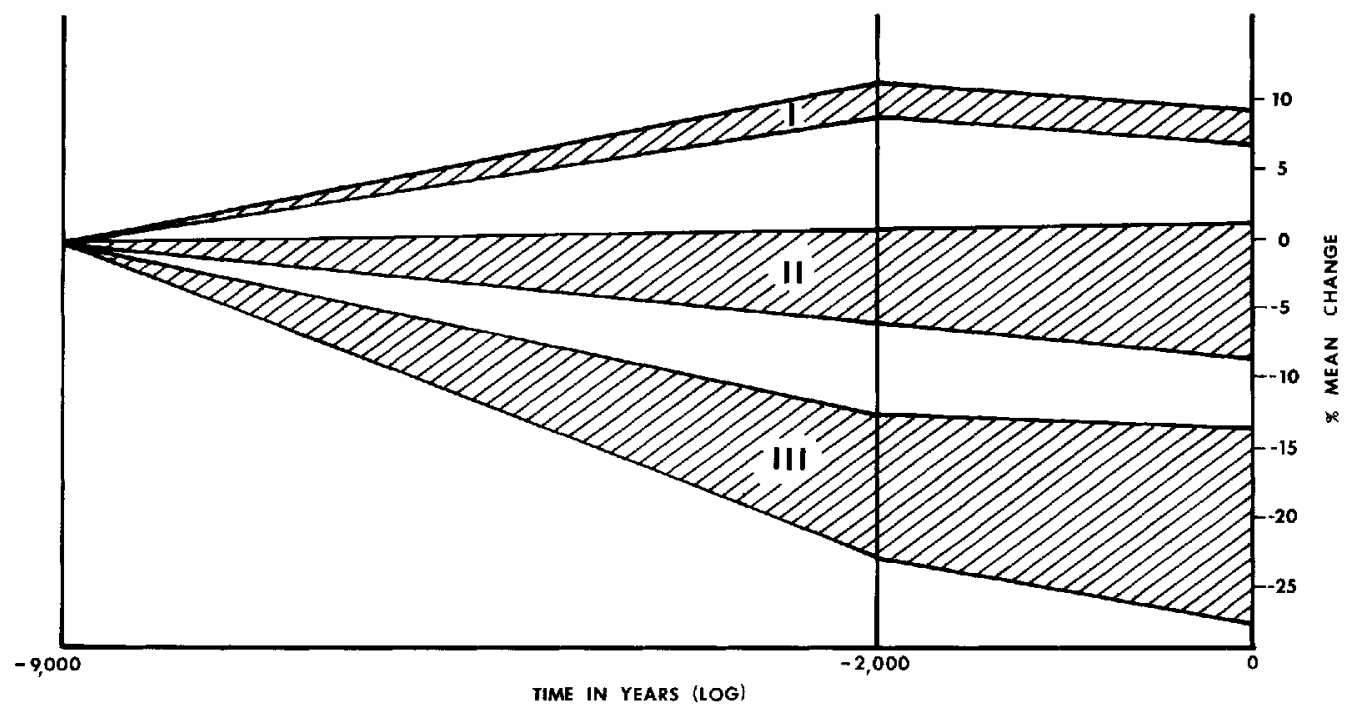

Fig. 3 Mean change in craniofacial dimensions (in percent) from the Mesolithic $(-9,000$ years) through the A-Group/C-Group ( $-2,000$ years) and Meroitic/X-Group/Christian periods $(0)$ plotted as a $\log$ function of time. Note that there are three relatively distinct clusters of variables. Cluster I (parietal chord, frontal chord, cranial height, and total facial height) shows a moderate increase in dimension over time, Cluster II (upper facial height, facial length, cranial length, symphyseal height, coronoid height, ramus height, cheek height and sigmoid height) contains variables that underwent a slight-to-moderate decrease through time; Cluster III (ramal width, symphyseal thickness, corpus length, masseter length) variables underwent a considerable decrease through time. Actual values for change in each of the 16 variables are listed in table 4.

relationship to mandibular size and shape, masseter origin length and vault length. In other words, any change in the first group of variables was associated with an opposite change in the latter group. For example, crania with relatively large mandibles also had a relatively large masseter and long cranial vault. Conversely, a skull with a relatively short, high vault also had a smaller mandible and a decreased size of the origin of the masseter muscle.

\section{DISCUSSION}

Evidence for the nature of craniofacial change from the Mesolithic population through the A-C and MXCh groups is provided by both the weighted variables along the first discriminant axis and by the mean values for all 16 variables (table 1).

The degree of mean change for each variable between the Mesolithic, the A-C group and the MXCh group is provided in table 4 and summarized graphically in fig. ure 4 as a logarithmic function of time.
Three distinct clusters of variables were apparent as they changed in dimension from the Mesolithic period (fig. 3). Four variables concerned with the relative height of the cranial vault and face were shown to increase over time (Cluster I: fig. 3). Another four variables, all concerned with masticatory robusticity, decreased greatly through time (Cluster III: fig. 3). The remaining eight variables, primarily concerned with craniofacial length and mandibular height, revealed very little change through time, although there was also a clear tendency for a slight decrease in size here (Cluster II: fig. 3). Each cluster contained variables substantially weighted by the first discriminant function. Thus, the function did not simply describe the extreme differences between the groups, but provided insight into the most important variables as they covaried according to a particular pattern of variation through time.

In summary, the pattern of craniofacial 




Fig. 4 Schematic diagram summarizing the changes in Nubian crania from the Mesolithic: (solid line) through the $\mathrm{MXCh}$ (dashed line) periods that are accounted for by the masticatory-functional hypothesis. The morphological changes involved, in order of importance, are: (1) a reduction in the size of the inuscles of mastication and a relatively more posterior site of origin; (2) a reduced anteroposterior growth of the maxillomandibular complex; and (3) a reduction in the relative length and incrcase in the relative height of the cranial vault which was compensatory to the altered vault-face relationship. A fourth change, reduction in the size of the teeth, is not shown here.

change in the Nubian skull since the Mesolithic shows the following: (1) a clear trend over the past 12,000 years for a relative increase in height and decrease in length of the cranial vault; (2) a definite tendency for the midface and lower face to become more inferoposteriorly located relative to the anterior cranial vault; and (3) a distinct decrease in the robusticity of the entire craniofacial complex, especially in those features primarily associated with masticatory function.

These three trends since the Mesolithic are identical to those described in an earlier analysis of craniofacial change from the A-Group horizon through the Christian horizon (Carlson, '76a), a period of approximately 5,000 years. This study thus reconfirms the trends, and suggests that change in craniofacial morphology since the Mesolithic in Nubia can be accounted for by the same patterns of variation.

\section{Masticatory-functional hypothesis}

It was suggested previously that change in masticatory function, leading to a relative decrease in the size and robusticity of the masticatory complex, was of primary importance in bringing about the changes in the cranial vault and facial complex noted above. Progressive decrease in the size and robusticity of the mandible and masticatory apparatus is the dominant feature in the transition from the Mesolithic period through the Christian horizon in Nubia. For example, nine of the 11 variables which decreased in size since the Mesolithic can be directly related to mas- 
ticatory function. Additionally, three of the six substantially weighted variables identified by the first discriminant axis are directly associated with the masticatory complex. Thus, the masticatory-functional hypothesis receives support from consideration of variables both on an individual basis and within the context of a multivariate analysis of all the craniofacial variables.

The hypothesis that change in masticatory function and diet was a primary factor in craniofacial evolution in Nubia is supported also by the dental evidence. Greene (Greene et al., '67; Greene and Scott, '73) hypothesized that the exceptionally large and morphologically complex dentition of the Nubian Mesolithic population was the result of strong selection for optimal resistance to the extreme attrition that results from a gritty diet and intense masticatory forces acting on the dentition. According to Greene and co-workers, dental change from the Mesolithic through relatively recent times can be explained by an increasing reliance on softer, more cariogenic foodstuffs. Thus, decreased masticatory forces and selection for more caries-resistant teeth resulted in a smaller and morphologically less complex dentition.

Emphasis on dental changes in Nubia over the past 12,000 years implies the primacy of these changes as a cause of morphological change in the skeletal component of the craniofacial complex as a whole. Systematic change in subsistence and diet undoubtedly brought about change in masticatory function, and Greene's hypothesis that this transition led to selection for morphologically less complex caries-resistant teeth is definitely a strong possibility. However, this hypothesis alone cannot account for dental size reduction within the Nubian population. Dental morphology is known to be under relatively strong genetic control (Kraus and Jordan, '65), and phylogenetic change in this feature among the Nubians is most likely to be the result of direct selective pressures for less complex teeth. Similarly, dental size is known to be under relatively rigid genetic control (Krogman, '67; Garn et al., '67; Garn et al., '68). However, the relationship between dental size, the morphological complexity of individual teeth and facial size and form is unclear (Ashton and Zuckerman, '51; Ashton, '64; Goodman, '65; Harris et al., '73; Krogman, '67).

A more inclusive approach to dental and skeletal change in Nubia should emphasize the interrelated nature of these three factors within the craniofacial complex. Considerable evidence from comparative studies and from the fossil record shows that the size and form of the maxillomandibular complex may have a major effect on the expression of dental size (Riesenfeld and Siegel, '70; Siegel, '72; Wolpoff, '75, '76). Whereas the traditional view that dental size is a primary determinant of jaw size is still widely accepted, there is growing evidence that the converse is equally true, at least in terms of the evolution of the face and jaws. Several recent studies indicate that reduction in the size of the teeth during hominid evolution may be the result of reduction in the size of the face (Sofaer et al., '71; Sofaer, '73; Anderson et al., '75; Wolpoff, '76). While the precise mechanisms by which reduction in facial size might bring about reduction in dental size are unclear, those suggested all tend to emphasize developmental interactions during growth in general (Hunt, '66; Anderson et al., 75) and during growth and evolution of the teeth and jaws in particular (Sofaer et al., 71; Siegel, '72; Sofaer, '73; Wolpoff, '76).

These considerations suggest that progressive alteration of the Nubian craniofacial complex over the past 10,000 years is probably the result of two relatively independent processes. The first, involving selection for morphologically less complex caries-resistant teeth, resulted only in a change in the morphology of the dentition. The principal factor influencing craniofacial evolution in Nubia can be perceived most accurately with the masticatory-functional hypothesis. According to this interpretation, a shift in subsistence adaptation of the Nubian population through 
time resulted in a decrease in the functional demands placed on the masticatory complex, and this in turn brought about three related alterations of craniofacial morphology. These include, in order of importance: (1) a reduction in the size of the muscles of mastication and relatively more posterior sites of origin; (2) a reduction in the growth of the maxillomandibular complex, such that the midface and lower face came to occupy a more inferoposterior location relative to the cranial vault; (3) a change in the shape of the cranial vault compensatory to the maxillomandibular change, such that the vault became relatively shorter and higher (more "globular"); and (4) a compensatory reduction in the size of the teeth and associated alveolar region due to the reduced anteroposterior growth of the maxillomandibular complex. The craniofacial features associated with this transition are summarized schematically in figure 4 .

There are a number of problems associated with the type of analysis where fossil and skeletal remains are called upon to "test" a hypothesis concerning evolutionary change. Secular or evolutionary modification of morphology, whatever the causative agent, is the direct result of progressive alteration of patterns of growth and development. As noted by Dahlberg, however: "it is not possible to discuss growth and development of fossil skulls or collections of skeletal materials, in the accepted sense. . . . Past elements of change leave records in bones and teeth, but do not afford the opportunity to observe ongoing process" ('65: p. 151).

Because of these and other limitations inherent in the analysis of fossil and skeletal remains from an evolutionary perspective (e.g., sampling), statements of probability for alternative evolutionary hypotheses are not possible. This does not mean, however, that such hypotheses are invalid or inappropriate. The primary value of the evolutionary hypothesis is to stimulate meaningful questions about evolution, not to provide the data for their proof. In fact, formulation and testing of hypotheses on the same body of data is obviously an exercise in tautology. It is possible, however, to construct an evolutionary model based on the analysis of fossil and skeletal remains as a testable hypothesis. According to Wolpoff (76), to maximize this approach it is necessary to observe at least three broad criteria: (1) detailed knowledge of the function of those characters which have undergone change; (2) detailed understanding of the ecology of the group(s) under analysis; and (3) a relatively large body of data from temporally distinct samples.

The present analysis of craniofacial change in Nubia should be viewed in light of the above comments. The masticatoryfunctional hypothesis is offered not only as a means of accounting for morphological change in Nubia, but also as an evolutionary model with more general implications. That this approach is warranted is demonstrated by the degree to which it meets the above criteria for the formulation of evolutionary hypotheses.

(1) The general interrelationships between the function of the masticatory complex and the form of the craniofacial complex are well known (e.g., Scott, '57; Endo, '65, '66; McNamara, 72; Moore and Lavelle, '74; Krogman, '76). Craniofacial change similar to that observed among the Nubians is a general trend seen in the evolution of the recent human skull. Furthermore, the view that such change is primarily related to a reduction in masticatory stress has widespread acceptance (e.g., Robinson, '54; Dahlberg, '65; Brace, '67; Wolpoff, '75).

(2) Extensive archaeology of the Lower Nile region has provided the most extensive and complete knowledge of prehistory and cultural ecology of any area in the world.

(3) The completeness of the archaeological record and the excellent preservation in Nubia have both contributed to the existence of relatively large and well-provenienced skeletal samples spanning the last $10-12,000$ years of Nubian prehistory.

These results do not prove the mastica- 
tory-functional hypothesis. Given our present understanding of Nubian prehistory, however, the hypothesis adopted here may best account for the changes in Nubian craniofacial morphology and their ramifications in light of bio-cultural adaptation. The masticatory-functional hypothesis thus stands as an evolutionary model with more general implications for the evolution of the hominid skull.

\section{ACKNOWLEDGMENTS}

The authors would like to gratefully acknowledge the assistance of David Burr, Arthur Rohr and Meredith Small in the preparation of this manuscript. A version of this paper was presented before the staff of the Center for Human Growth and Development, and we are indebted to this group for their rigorous critique. Editorial assistance and typing of the final draft was provided by Ms. Carole Bride and Ms. Donna Monroe.

\section{LITERATURE CITED}

Adams, W. Y. 1967 Continuity and change in Nubian culture history. Sudan Notes and Records, 48: $1-32$

1970 A re-appraisal of Nubian culture history. Orientalia, 39: 269-277.

Anderson, D. L., G. W. Thompson and F. Popovich 1975 Evolutionary dental changes. Am. J. Phys. Anthrop., 43: 95-102.

Ashton, E. H. 1964 The influence of geographic isolation on the skull of the green monkcy (Cercopithecus aethiops sabaeus). V. The degree and pattern of differentiation in the cranial dimensions of the St. Kitts green monkey. Proc. Roy. Soc. B, 151:563-583.

Ashton, E. H., and S. Zuckerman 1951 The influenes? of geographic isolation on the skull of the green monkey (Cercopithecus aethiops sabaeus) II. The cranial dimensions of the St. Kitts and the African green monkey. Proc. Roy. Soc. B, 138: 204-212.

Billy, G. 1975 Principal Population Changes between Egypt and Nubia up to the Roman Period LAnthropologie, 79: 629-657.

Brace, C. L. 1967 Environment, tooth form, and size in the Pleistocene. J. Dent. Res., 46: 809-816.

Burnor, D. R., and J. E. Harris 1968 Racial continuity in Lower Nubia: 12,000 to the present. Proceedings of the Indiana Academy of Science 1967, 77 : 113-121.

Carlson, D. S. $1974 a$ Temporal Variation in Prehistoric Nulvian Crania. Unpublished Ph.D. Dis sertation. University of Massachusetts. 1974b Craniofacial change in early Nubia: Implications for understanding morphological change in the hominid skull. Am. J. Phys. Anthrop. 41:471 (Abstract).

1976a Temporal variation in prehistoric Nubian crania. Am. J. Phys. Anthrop., 45: 467-484. 1976b Patterns of morphological variation in the human midface and upper face. In: Factors Affecting the Growth of the Midface. J.A. MeNamara, ed. Center for Human Growth and Development, Craniofacial Growth Series Monograph No. 6, Ann Arbor, pp. 277-299.

Crichton, J. M. 1966 A multiple discriminant analysis of Egyptian and African Negro crania. Papers of the Peabody Mus. of Arch. and Ethnol. Harvard Univ., 57: 43-67.

Dahlberg, A. A. 1965 Evolutionary background of dental and facial growth. J. Dent. Res. (Suppl. 1), 44: $151-160$

Endo, B. 1965 Distribution of stress and strain produced in the human facial skeleton by masticatory force. J. Anthrop. Soc. of Nippon (Zinruigaka Zassi), 73: $123-136$

1966 Experimental studies on the mechanical significance of the form of the human facial skeleton. J. Fac.Sci., Univ. Tokyo (Sec. V), 3: 1-106

Garn, S. M., A. B. Lewis and A. J. Walenga 1968 Genetic basis of the crown-size profile pattern. J. Dent. Res., 47: 1170

Garn, S. M., D. Swindler and R. S. Kerewsky 1967 Genetic control of sexual dimorphism in tooth size J. Dent. Res. (Suppl.), 46; 963-972.

Goodman, H. O. 1965 Genetic parameters of den tofacial development. J. Dent. Res., 44: 174-184.

Greene, D. L. 1966 Dentition and the biological relationships of some Meroitic, X-Group and Christian populations from Wadi Halfa, Sudan. Kush, 14 $285-288$

1972 Dental anthropology of early Egypt and Vubia. J. Hum. Evol., 1: 315-324.

Greene, D. L., and G. J. Armelagos 1972 The Wadi Halfa Mesolithic Population. Research Report No. 11. Department of Anthropology, University of Massachusetts, Amherst.

Greene, D. L., G. H. Ewing and G. J. Armelagos 1967 Dentition of a Mesolithic population from Wadi Halfa, Sudan. Am. J. Phys. Anthrop., 27: 41-56.

Greene, D. L., and L. Scott 1973 Congenital frontal sinus absence in the Wadi Halfa Mesolithic population. Man, 8: 471-474.

Harris, J. E., C. J. Kowalski and S. S. Watnick 1973 Genetic factors in the shape of the craniofacial complex. Angle Orthod., 43: 107-111.

Hunt, E. E. 1966 The developmental genetics of man. In: Human Development. F. Falkner, ed. Saunders, Philadelphia, pp. 76-122

Kraus, B. S., and R. E. Jordan 1965 The Human Dentition Before Birth. Lea and Febiger, Philadelphia.

Krogman, W. M. 1967 The role of genetic factors in the human face, jaws and teeth: A review. The Eugenics Rev., 59: 165-192.

- 1976 Craniofacial growth and develop ment: An appraisal. Yearbook of Physical Anthropology, Vol. 18 (1974): 31-64. 
MeNamara, J. A., Jr. 1972 Neuromuscular and Skeletal Adaptations to Altered Orofacial Function. Center for Human Growth and Development, Craniofacial Growth Series Monograph No. 1, Ann Arbor.

Moore, W. J., and C. L. B. Lavelle 1974 Growth of the Facial Skeleton in the Hominoidea. Academic Press, London.

Morant, G. M. 1925 A study of Egyptian craniology from prehistory to Roman times. Biometrika, 17 : $1-52$.

1935 A study of pre-dynastic Egyptian skulls from Badari based on measurements taken by Miss B. N. Stoessiger and Prof. D. E. Derry. Biometrika, 27: 293-308.

Riesenfeld, A., and M. I. Siegel 1970 The relationship between facial proportions and root length in the dentition of dogs. Am. J. Phys. Anthrop., 33: 429. 432 .

Robinson, J. T. 1954 Prehominid dentition and hominid evolution. Evolution, 8: 324-334.

Scott, J. H. 1957 Muscle growth and function in relation to skeletal morphology. Am. J. Phys. Anthrop., 15: 197-233.

Siegel, M. I. 1972 The relationship between facial protrusion and root length in the dentition of baboons. Acta. Anat., 83: 17-29.

Sofuer, J. A. 1973 A model relating developmental interaction and differential evolutionary reduction in tooth size. Evolution, 27:427-434.
Sofaer, J. A., H. L. Bailit and C. J. MacLean 1971 A developmental basis for differential tooth reduction during hominid evolution. Evolution, 25: 509-517.

Vagn Nielsen, O. 1970 Human Remains. Metrical and Non-Metrical Anatomical Variations. The Scandanavian Joint Expedition to Sudanese Nubia, Vol 9. Scandanavian University Books. Munksgaard, Copenhagen.

Van Gerven, D. P., D. S. Carlson and G. J. Armelogos 1973 Racial history and bio-cultural adaptation of Nubian archeological populations. J. Afr. Hist., 14 : 555-564

Wendorf, F., J. L. Shiner and A. E. Marks 1965 Summary of the 1963-1964 field season. In: Contributions to the Prehistory of Nubia. F. Wendorf, ed. Publ. No. 4, Fort Burgwin Res. Center, Southern Methodist University Contributions in Anthropology, No. 1: ix-xxxy.

Wolpoff, M. H. 1975 Some aspects of human mandibular evolution. In: Determinants of Mandibular Form and Growth. J. A. McNamara, ed. Center for Human Growth and Development. Craniofacia Growth Series Monograph No. 4, Ann Arbor, pp. 164.

1976 Evolutionary aspects of hominid tooth reduction and early hominid dental variation. In: Les Plus Anciens Hominides. P. Tobias and Y. Coppens, eds. Ctr. Nat. de la Res. Scientific, Paris, pp. 318-406. 